\title{
Prediction of the shelf-life of date seeds brew by integration of acceptability and quality indices
}

\begin{abstract}
The storage shelf life of brews has become progressively important in recent years for the beverage's manufacturers. The objectives of this study were to investigate the proximate composition and mineral contents of the proposed roasted date seeds powders, to model the kinetic changes in the properties of the brews during storage and to establish a predictive model for forecasting the shelf life by integration of consumer acceptability and quality attributes of the brews. Foremost, the chemical composition and mineral content analysis of both full fat and low-fat powders were investigated using the standard methods. The brews were prepared using hot water and then stored up to 30 days at $4,25,38{ }^{\circ} \mathrm{C}$. Samples of brews were taken initially and after 2, 4, 6, 12, 18, 24 and 30 days for conducting $\mathrm{pH}$ measurement and sensory evaluation. Kinetic modelling for the properties were conducted by applying the nonlinear regression technique. Besides, the shelf life of the brews was predicted by integration of the acceptability and quality indicators. The results revealed that $\mathrm{pH}, \mathrm{H} 3 \mathrm{O}+$ and sensory attributes of the brews were significantly influenced by the storage conditions. Descriptive models have been developed for describing the different properties and the shelf life of brews. In addition, the brews were microbiologically stable during the predicted shelf life period under different storage temperatures and times.
\end{abstract}

Keyword: Date seeds; Brew; Storage; Shelf life; Modelling 